\title{
The effects of exercise to promote quality of life in individuals with traumatic brain injuries: $A$ systematic review
}

\author{
Authors \\ *Corresponding author: stephanie.king@hull.ac.uk \\ Sport, Health and Exercise Science \\ University of Hull \\ Cottingham Road \\ Hull HU6 7RX
}

Grace C. O’Carroll ${ }^{1}$, Stephanie L. King ${ }^{1 *}$, Sean Carroll ${ }^{1}$, John L. Perry ${ }^{2}$ and Natalie Vanicek ${ }^{1}$

${ }^{1}$ Department of Sport, Health and Exercise Science, University of Hull, United Kingdom.

${ }^{2}$ Psychology Department, Mary Immaculate College, Republic of Ireland.

There are no conflicts of interest to declare. The authors did not receive any funding in the preparation of this review. 
This is an Accepted Manuscript of an article published by Taylor \& Francis in Brain Injury on 15 Nov 2020, available online: https://doi.org/10.1080/02699052.2020.1812117

\section{Abstract}

Objective: To systematically review the effects of exercise interventions that may enhance quality of life (QOL) in individuals with traumatic brain injury (TBI).

Methods: A systematic search of the literature was conducted using five databases up to April 2018. Studies were included if QOL was quantified following an exercise programme for people with a TBI. Methodological quality was assessed using a validated scoring checklist. Two independent reviewers assessed study inclusion and methodological quality.

Results: Thirteen studies met the inclusion criteria (7 RCTs and 6 non-RCTs). The median total scores for the quality assessment tool were 26.1 (RCTs), and 21.3 (non-RCTs), out of 33. Eight out of the 13 studies reported improved QOL following an exercise programme. The duration of the interventions varied from 8-12 weeks. The most common programmes involved moderate to vigorous exercise; with a frequency and duration of 3-5 times/week for 30-60 minutes.

Conclusion: Due to the diversity of the exercise training interventions, heterogeneity of TBI patient characteristics, multitude of QOL instruments and outcome domains assessed, it was not possible to draw any definitive conclusion about the effectiveness of exercise interventions. However, this review identified positive trends to enhance various aspects of QOL measured using a broad range of assessment tools. 
This is an Accepted Manuscript of an article published by Taylor \& Francis in Brain Injury on 15 Nov 2020, available online: https://doi.org/10.1080/02699052.2020.1812117

\section{Introduction}

Traumatic brain injury (TBI) is a global health issue with at least 10 million annual cases, and a major cause of disability, morbidity and mortality ${ }^{(1,2)}$. Following a head injury, long term consequences can affect the physical, cognitive, behavioural, and emotional functions of the individual causing reduced motor control/balance, sensation deficits, and issues with speech $^{(1)}$. In addition, TBI individuals are significantly more likely to report adverse lifestyles, including sedentary behaviour ${ }^{(3)}$, binge drinking ${ }^{(4)}$, and more vulnerable to experiencing fatigue, depression ${ }^{(5)}$, high levels of self-reported anxiety, or generalised anxiety disorders, epilepsy ${ }^{(4)}$ and developing early Alzheimer's ${ }^{(6)}$. These issues can result in relationship breakdowns ${ }^{(7)}$, job losses ${ }^{(8)}$ and homelessness ${ }^{(9)}$, leading to significant social stigma and socioeconomic consequences, with financial burdens on the healthcare system.

Quality of life (QOL) is a subjective measure, taking into consideration the individuals' perception of their physical, cognitive and affective states, interpersonal relationships and social roles in their lives ${ }^{(10)}$. The World Health Organisation QOL questionnaire also includes a spiritual dimension, which examines an individual's perception of 'meaning of life' and overarching personal beliefs ${ }^{(10)}$. Accordingly, QOL is a very complex and broad-ranging concept, affected by physical health, independence, psychological state of mind, beliefs, and social relationships. However, in broad terms, QOL has been defined as an "individuals' perception of their position in life in the context of the culture and value systems in which they live and in relation to their goals, expectations, standards and concerns"(10,p1405). QOL outcome measures are important within head injury research ${ }^{(11,12)}$ as individuals with TBI report a lower QOL compared with the general population ${ }^{(13,14)}$.

Regular physical activity is well known for promoting a variety of health benefits including improvements to cardiorespiratory fitness ${ }^{(15)}$, lower mortality rates ${ }^{(16)}$, reduced depressive 
This is an Accepted Manuscript of an article published by Taylor \& Francis in Brain Injury on 15 Nov 2020, available online: https://doi.org/10.1080/02699052.2020.1812117

symptoms ${ }^{(17)}$, and enhancing overall psychological well-being ${ }^{(18)}$ in healthy individuals. Regular exercise, which is a planned, structured form of physical activity, has also been shown to enhance cognitive functioning and facilitate neuroplasticity ${ }^{(19)}$. For these reasons, exercise training has been suggested to play a key role in the rehabilitation of individuals following a TBI.

Better physical functioning, and participation in fulfilling activities, such as social interactions and returning to employment, have previously indicated QOL improvements following a $\mathrm{TBI}^{(20,21)}$. Additionally, physical activity is reportedly an effective treatment modality for reducing anxiety and somatic conditions in both healthy and TBI individuals ${ }^{(22)}$. Due to the positive effects of exercise and physical activity on an individuals' QOL, it has been considered a health-promoting self-care behaviour.

Despite the extensive research in TBI rehabilitation, there is still disagreement about the most effective exercise modality and general exercise principles in terms of frequency, intensity, time, and type (FITT) of exercise intervention and the impact this could have on QOL outcomes.

\section{Aim}

The overarching aim of this systematic review was to evaluate exercise training interventions that may enhance QOL in individuals following a TBI. The main objective was to report on the effects of structured exercise training on QOL outcomes within adults following TBI. Secondly, we reviewed the exercise intervention characteristics (FITT principles) within published studies with QOL as an outcome measure and the different QOL tools used as study outcome variables. The overall quality of the published exercise training studies in adults following TBI were evaluated. 


\section{Methods}

This systematic review was undertaken and reported in accordance with the general principles recommended in the Preferred Reporting Items for Systematic Reviews and Meta-Analyses (PRISMA) statement ${ }^{(23)}$.

\section{Search strategy}

The evidence-based PICO model ${ }^{(24)}$ was used to help formulate the clinical question. The determinants are outlined in Table 1.

All forms of study designs were included apart from systematic and narrative review articles, and guideline papers, to maximise available data. Database searches were conducted in PubMed, Web of Science, Scopus, Cochrane, and ProQuest. The specific search terms used were "traumatic brain injury", "TBI", "exercise", "physical activity", and "quality of life". The complete set of Boolean operators is outlined in Appendix 1. We searched the databases for article published between 1900 and April 2018.

\section{[Insert Table 1.]}

\section{Data extraction and synthesis}

Following the database searches and the deletion of duplicates, initially the article titles were screened against the inclusion and exclusion criteria, followed by the abstracts and then a full-text review of potentially included articles against the specific criteria. The final selection of articles, where QOL was an outcome measure, were analysed independently by two reviewers $(\mathrm{GO}, \mathrm{SK})$. No disagreements were encountered and therefore a third reviewer was not required to act as an adjudicator. The data were extracted and organised by category: study identification, aim, participant characteristics and sample size, intervention characteristics, QOL outcome measures, and results. 


\section{Outcomes measures}

The primary outcome of this systematic review was to report on the effectiveness of the exercise training programmes in improving QOL in adults following a TBI. Secondly, the characteristics of the exercise interventions were reviewed. Our review considered the setting where the exercise intervention was delivered and detailed the FITT (Frequency, Intensity, Time, and Type) principles of the structured exercise programme. This review was conducted to evaluate whether the FITT principles influenced QOL outcomes within TBI patients. The different QOL tools utilised to evaluate the effects were exercise interventions were reviewed.

To be considered for inclusion in this systematic review, QOL assessment tools must have presented information related to at least one of the following domains: 1) physical functioning, 2) psychological or mental function, 3) social and economic function, 4) pain, 5) vitality, and 6) general health perceptions. This included (but not limited to) tools that measured depression, anxiety, stress, social interactions, sleep quality, and functional independence. QOL was quantified using validated questionnaires, including a mixture of generic or condition-specific scales developed to measure overall QOL and domains of QOL.

\section{Quality assessment}

The methodological quality of the included studies was assessed using a checklist developed by Downs \& Black ${ }^{(25)}$ which is suitable for both randomised and non-randomised studies of healthcare interventions. It consists of several components including: (1) Reporting (ten items): assessing whether the information provided is sufficient; (2) External Validity (three items): addressing the extent to which the findings could be generalised to the population; (3) Bias (seven items): addressing biases in the measurement of intervention and outcomes; (4) Confounding (six items): assessing bias in the selection of study subjects; and (5) Power (one 
This is an Accepted Manuscript of an article published by Taylor \& Francis in Brain Injury on 15 Nov 2020, available online: https://doi.org/10.1080/02699052.2020.1812117

item): assessing whether the negative findings could be due to chance. Answers were scored $0-1$, except for one item in the Reporting component (scored 0-2) and the Power subscale (scored 0-5). The total maximum score was 33. Overall scoring can be categorised into good $(>20)$, moderate $(11-20)$ and poor $(<11)$ methodological quality ${ }^{(25)}$. The methodological quality was assessed by two independent reviewers with any disagreements being resolved before continuation of the analysis.

\section{Results}

\section{Search results}

The initial search returned 5128 articles (Web of Science: 1309, PubMed: 1804, Scopus: 1581, Cochrane: 238 and ProQuest: 196). The duplicate articles (2023) were identified and excluded, leaving 3105 studies for the initial stage of the review (Figure 1). Both reviewers screened 43 full-text articles, with 30 articles being excluded (Figure 1). The remaining 13 studies were included in the final analysis according to the unanimous decision of the two reviewers.

\section{[Insert Figure 1.]}

\section{Quality assessment}

The quality of the methodologies reported within the primary studies was assessed and analysed separately for the RCT and the non-RCTs (Table 2). All of the RCT

studies ${ }^{(26,27,28,29,30,31,32)}$ had total scores $>20$, categorised as 'good', ranging from $22^{(30)}$ to $29^{(29)}$. All seven articles reported clear descriptions of their main outcomes, interventions, principle confounders, exact probabilities, and reported external validity. Of the seven RCT studies, Bateman et al. ${ }^{(26)}$, Bellon et al. ${ }^{(31)}$, and Hassett et al. ${ }^{(29)}$ scored highest on internal validity 
(bias), with Elsworth et al. ${ }^{(28)}$ and Hassett et al. ${ }^{(29)}$ scoring highest for internal validity (confounding). The lowest ratings were for internal validity (confounding) sub-sections, with only one study using an assessor-blinded randomisation design ${ }^{(29)}$ and only one study presenting confounding adjustment ${ }^{(28)}$. For the four non-RCTs, the total scores ranged from $18^{(33,34)}$ to $25^{(37)}$. All six non-RCTs ${ }^{(33,34,35,36,37,38)}$ reported clear descriptions of their main outcomes, patient information, intervention, findings, and presented the study group approached and included. Damiano et al. ${ }^{(35)}$ and Lee et al. ${ }^{(37)}$ scored highest on external validity, with Kleffelgaard et al. ${ }^{(33)}$, Lee et al. ${ }^{(37)}$, Schwandt et al. ${ }^{(34)}$, and Weinstein et al. ${ }^{(38)}$ scoring highest on internal validity (confounding) of all the six non-RCTs. However, Kleffelgarrd et al. ${ }^{(33)}$ scored the lowest for internal validity (bias). Similar to the RCT studies, the lowest ratings were for two of the internal validity (confounding) sub-sections; hidden randomisation and confounding adjustments. By default, all non-RCTs scored zero (attributed 'no') for randomisation. Additionally, all 13 studies scored zero (attributed 'no') for blinding the participants to the intervention they received. This aspect of research design is inherently challenging as all the interventions involved structured exercise.

\section{[Insert Table 2.]}

\section{Study characteristics}

\section{Participants}

The number of participants recruited to the primary studies varied from 4 to 157 adult neurological patients; with 4 to 69 undertaking structured exercise across all 13 eligible studies (Table 3). All 13 studies included both female and male participants, with an age range between 24 and 65 years, and three studies included more women than men ${ }^{(30,37,38)}$. Ten out of the 13 primary studies investigated the effects of exercise intervention on adults following TBI exclusively ${ }^{(29-38)}$, while the remaining three articles grouped together a variety 
This is an Accepted Manuscript of an article published by Taylor \& Francis in Brain Injury on 15 Nov 2020, available online: https://doi.org/10.1080/02699052.2020.1812117

of brain-related injuries that included $\mathrm{TBI}^{(26-28)}$. One study ${ }^{(26)}$ included participants who had suffered strokes and haemorrhages, whereas another included various neurological disorders, including Parkinson's disease, multiple sclerosis, motor neurone disorders, and cerebral palsy $^{(28)}$. One study ${ }^{(27)}$ did not specify the nature of the brain-injury amongst participants, but specified that the majority of participants required a wheelchair or walking frame/aid for mobility purposes. For those studies reporting data, the severity of the TBI ranged from mild to severe (Glasgow Coma Score of 13-15 for mild, 9-12 for moderate and 3-8 for severe) across the 13 studies. Nine out of the 13 , reported on cases where the time since injury was six months or longer ${ }^{(27,30-32,34-38)}$, with two studies including participants who had sustained the injury in under six months ${ }^{(26,29)}$. Two studies did not specify the time since injury ${ }^{(28,33)}$. All the studies were conducted in countries with well-developed healthcare systems, including US, Canada, Australia, Norway, and UK.

\section{[Insert Table 3.]}

\section{Interventions}

The duration of the exercise interventions was short-term, ranging from eight to twelve weeks across all studies (Table 4). Individual exercise sessions ranged from 30 to 90 minutes duration with frequencies ranging from one to five times per week. The most common exercise programme involved exercise sessions lasting 30 minutes, performed three times weekly ${ }^{(26,34,36,38)}$. One study did not specify the duration or the frequency of the sessions ${ }^{(31)}$. Five studies demonstrated relatively good completion rates of $77 \%{ }^{(29)}, 78 \%{ }^{(34)}, 93 \%{ }^{(36,38)}$ and $>80 \%{ }^{(35)}$ for the exercise interventions. Lee et al. ${ }^{(37)}$ reported an average attendance of $71 \%$ over the 8 week supervised IntenSati programme, with Blake et al. ${ }^{(32)}$ outlining their exercise group completed $58 / 80$ sessions $(73 \%)$ over the 8 weeks. In one case series ${ }^{(33)}$, the four participants attended between 8 and 15 sessions out of the maximum 16. During the 
This is an Accepted Manuscript of an article published by Taylor \& Francis in Brain Injury on 15 Nov 2020, available online: https://doi.org/10.1080/02699052.2020.1812117

supervised sessions in one study ${ }^{(30)}$, only 5.9 (from 10) sessions were attended over the 10 weeks. The RCT of Bateman and colleagues ${ }^{(26)}$ outlined that the average total minutes of exercise performed by the exercise group was 552 minutes, which was only half of the prescribed maximum. One study documented a considerably lower number of exercise sessions performed per week, with only $44 \%$ partaking in $\geq 1$ session, $8 \% \geq 2$ sessions and $2 \%$ $\geq 3$ sessions $^{(28)}$. Two studies did not present any adherence rates ${ }^{(27,31)}$.

All of the studies delivered supervised, structured exercise programmes with the exception of two, whereby one encouraged an unsupervised, but supported self-directed exercise intervention at the local gymnasium ${ }^{(28)}$. The other study promoted a home-based walking programme with coaching contact via telephone/email ${ }^{(31)}$. Three studies ${ }^{(29,30,33)}$ included both supervised and unsupervised (home-based) exercise sessions. Eight of the 13 studies included different types of aerobic-based exercises (aquatic aerobics/resisted exercise, treadmill walking/running, stationary biking, stair-stepping, rowing, track running) as part of the intervention $^{(26,27,28,30,31,34,36,38)}$; with four studies concentrating on motor control, balance, and strength and conditioning training ${ }^{(32,33,35,37)}$. The study by Hassett et al. ${ }^{(29)}$ combined both strength-based and aerobic exercise in their exercise sessions. The prescribed intensity of the exercise sessions across the primary studies was moderate to vigorous intensity, ranging from $50-80 \%$ of maximum heart rate $(\mathrm{HRmax})^{(39)}$. One article used RPM to gauge exercise intensity, where participants maintained 40-80 rpm against resistance on an elliptical trainer $^{(35)}$. Another paper categorised intensity as a weekly $5 \%$ increase in number of steps, initiated from their baseline data ${ }^{(31)}$. Hassett et al. ${ }^{(29)}$ categorised their cardiorespiratory intensity as moderate (heavy breathing but could talk). Four studies did not report exercise intensities ${ }^{(28,33,37,38)}$. Nine of the 13 studies included a control or usual care group ${ }^{(26-32,36,37)}$. Bateman et al. ${ }^{(26)}$, Driver et al. ${ }^{(27)}$, Hassett et al. ${ }^{(29)}$, Bellon et al. ${ }^{(31)}$, and Blake et al. ${ }^{(32)}$ provided their control groups with alternative activities (relaxation therapy, vocational rehabilitation 
classes, home-based exercises, nutritional programme, and non-exercise social and leisure activites, respectively). Elsworth et al. ${ }^{(28)}$, Hoffman et al. ${ }^{(30)}$, Damiano et al. ${ }^{(35)}$, and Lee et al. ${ }^{(37)}$ did not specify the 'standard care' provided to their control groups. Whereas, the remaining four studies only presented findings for the intervention group ${ }^{(33,34,36,38)}$.

\section{[Insert Table 4.]}

\section{Outcome Measures}

\section{Quality of life}

The primary outcomes were QOL assessment or related domain specific tools for $11^{(26,27,30-38)}$ of the 13 studies, with the remaining two specifying QOL as their secondary outcomes ${ }^{(28,29)}$. A total of 28 different QOL-related instruments were used across all 13 studies. There was only one study that incorporated a tool measuring overall QOL in relation to TBI specifically: the Quality of Life in Brain Injuries questionnaire (QOLIBRI) ${ }^{(33)}$. The remaining tools that were used measured various domains affecting QOL (e.g., anxiety, depression, fatigue, mood, pain, etc.). The tools most frequently assessed was the Pittsburg Sleep Quality Index (PSQI) $(n=3 \text { studies })^{(30,35,36)}$, the Becks Depression Index $(B D I)(n=3)^{(30,36,37)}$ followed by the Profile of Mood States questioannire (POMS) $(n=2)^{(29,38)}$ and the Hospital Anxiety and Depression Scale (HADS) $(n=2)^{(26,33)}$. Nine out of the 13 studies measured their outcomes at baseline and post-intervention (two testing points). Four studies had additional follow-up assessments that included QOL tools ${ }^{(26,29,31,38)}$.

Five articles ${ }^{(28,29,30,32,37)}$ outlined significant improvements in the intervention group compared to the control group using the Short Form-36 (SF-36), POMS , Brief Pain Inventory (BPI), General Health Questionnaire-15 (GHQ-15), and the Positive and Negative Affect Scale (PNAS) tools. In addition, significant pre-post improvements for the intervention group were demonstrated with the Health Promoting Lifestyle Profile (HPLP-II) ${ }^{(27)}$, the Pittsburg Sleep 
This is an Accepted Manuscript of an article published by Taylor \& Francis in Brain Injury on 15 Nov 2020, available online: https://doi.org/10.1080/02699052.2020.1812117

Quality Index (PSQI) ${ }^{(35)}$, PNAS ${ }^{(37)}$, Life- $3^{(37)}$, POMS $^{(38)}$, GHQ-12 $2^{(32)}$, and the Physical Self-Description Questionnaire (PSDQ) $)^{(32)}$ tools.

\section{[Insert Table 5.]}

\section{Discussion}

This review has highlighted that exercise interventions can illicit positive improvements on several domains of QOL, such as sleep quality, mood, engaging in health-promoting lifestyles, pain, self-esteem, and community re-engagement. However, we found that only one non-randomised, uncontrolled series study ${ }^{(33)}$ utilised a QOL tool specifically for a TBI population (QOLIBRI). Overall, there was inconsistent and limited evidence from RCTs and other studies to confirm that structured, supervised outpatient exercise, combining aerobic exercise and resisted exercise components promoted positive changes in various indices related to QOL when performed for at least 90 to 180 minutes/week, and working at a prescribed moderate to vigorous intensity of $50-80 \%$ of age-predicted HRmax or equivalent ${ }^{(26,27,30,31,34,36,38)}$. In contrast, QOL domains and recovery of functional independence were reported to occur independently of inpatient aerobic training ${ }^{(28)}$.

The Downs and Black ${ }^{(25)}$ checklist presented 'good' overall scores for the majority of the exercise intervention studies included in this systematic review. Notably, only two of the eligible RCTs of exercise interventions recruited exclusively post-TBI participants but addressed very different research questions related to their exercise interventions. Specifically, Hassett et al. ${ }^{(29)}$ recruited 62 predominantly male $(85 \%)$ participants in their mid-thirties (recently discharged from inpatient neurological rehabilitation units following a very severe TBI), and randomised participants to a supervised, community-based exercise intervention, or home-based 'usual care' exercise programme. Their aim was to compare the effects of a supervised fitness centre-based exercise program with an unsupervised 
This is an Accepted Manuscript of an article published by Taylor \& Francis in Brain Injury on 15 Nov 2020, available online: https://doi.org/10.1080/02699052.2020.1812117

home-based exercise programme. In contrast, within a single-centre study, Hoffman et al. ${ }^{(30)}$ looked to test the hypothesis that a structured aerobic exercise programme would decrease the severity of depressive symptoms following a TBI. They randomised 84 adult TBI participants, (predominantly females exhibiting at least mild depressive symptoms), to a combined supervised community gymnasium/ home-based aerobic exercise intervention compared to a delayed-start control group. Furthermore, within the largest eligible multi-centre RCT of neurological patients, Bateman et al. ${ }^{(26)}$ conducted a post-hoc analysis investigating the impact of pathology, comparing TBI versus non-TBI patients within inpatient exercise rehabilitation. Together, these distinct RCTs represent the best quality evidence of the effectiveness of supervised inpatient, community, or home-based, and structured exercise training interventions on QOL outcomes following a TBI. Regarding the smaller non-RCTs, failure to report confounding adjustments contributed to a low-quality score. These lower scores were entirely expected for exercise-related interventions due to a default zero score allocated to the randomisation process and provided justification for our separate comparison of the methodological quality for the RCT and non-RCTs. For all 13 studies, it was impossible to blind participants to their allocated interventions (exercise treatments), although relaxation classes, vocational rehabilitation, delayed-start and home-based exercise served as alternative group comparisons.

Within their multi-centre study, Hassett et al. ${ }^{(29)}$ was the only investigation that reported conducting their exercise programme (combined aerobic and strengthening exercise) according to professional body ${ }^{(40)}$ guidelines for post-brain injury patients. Across all studies, the overall intervention periods were short, ranging from 8-12 weeks (30-60 min/session), with four out of the five programmes incorporating structured aerobic training, with supervised components. 
This is an Accepted Manuscript of an article published by Taylor \& Francis in Brain Injury on 15 Nov 2020, available online: https://doi.org/10.1080/02699052.2020.1812117

Hassett et al. ${ }^{(29)}$ reported no differences in supervised compared to home-based exercise interventions for cardiorespiratory fitness, or psychological functioning outcomes post-intervention or at follow-up. Likewise, significant group differences in community reintegration outcomes were not maintained at longer follow-up. Hoffman et al ${ }^{(30)}$ reported lower pain outcomes amongst mainly female post-TBI participants, but no significant differences in depression scores (BDI), general health status or perceived QOL between the exercise intervention and the delayed-start control group at 10 weeks. However, a subsequent report by Wise and colleagues ${ }^{(41)}$ showed exercise intervention participants maintained improvements in BDI scores over time. Approximately half (48\%) of their participants demonstrated increased physical activity at 6 months compared with baseline and those who exercised more than 90 minutes/week had lower scores on the BDI at the 10-week and 6-month assessments and reported higher perceived QOL and mental health outcomes ${ }^{(41)}$.

Eight of the 13 studies $^{(26-28,30,31,34,36,38)}$ incorporated different forms of aerobic exercise training, evidencing that a range of exercise modalities can promote positive changes to an individuals' QOL. Individuals who have suffered a TBI generally have a lower aerobic capacity compared with age- and gender-matched controls ${ }^{(42,43)}$, therefore a targeted exercise programme that includes aerobic training could enhance cardiorespiratory fitness outcomes ${ }^{(44)}$ and improve QOL domains concomitantly ${ }^{(26,27,30,33-35)}$.

However, due to the small number of studies that elicited significant changes, and the broad range of exercise modalities that were described, we were unable to reach a consensus on the optimum FITT principles, as described in our second objective, or to establish a clear and definitive exercise prescription. In addition, there was a lack of robust study designs; RCT designs are required to quantify and evaluate the effectiveness of different exercise interventions clinically. The effects of different exercise interventions following a TBI are 
This is an Accepted Manuscript of an article published by Taylor \& Francis in Brain Injury on 15 Nov 2020, available online: https://doi.org/10.1080/02699052.2020.1812117

widely researched ${ }^{(41,45-48)}$, but there remain contrasting views on the most appropriate exercise modality and exercise dose, highlighting the complexity of prescribing an individualised exercise programme following a TBI. Nevertheless, this systematic review has identified a range of exercise prescriptions that can enhance QOL and/or its related domains.

A further objective of this systematic review was to examine the different QOL tools used within the included studies. All the significant improvements were identified by tools that explored individuals' perceptions of different domains of QOL (HPLP-II, PSDQ, POMS, SF-36, BPI, BDI, PNAS, Life-3, GHQ-12). Bergquist and colleagues ${ }^{(49)}$ asked brain-injured individuals to define their views on QOL. Three major dimensions emerged: 1) achieving a sense of productivity; 2) establishing a sense of self-control, self-efficacy, and self-competency; 3 ) experiencing a sense of community among self, and others. The perception of QOL can differ greatly between individuals following a TBI, so measuring domains of QOL could be as important as overall QOL tools. Quality of life is a complex issue to discuss due to the many indicators that influence it, including material living conditions, governance, and basic rights ${ }^{(50)}$. This current review conceptualised QOL definitions by looking at the persons' physical, mental, social and economic functioning as well as pain, vitality and general health perceptions.

With few papers looking specifically at the effects of exercise on QOL in people with TBI, it is problematic for clinicians to make evidence-based decisions when prescribing exercise programmes. The effectiveness of exercise on QOL needs to be evaluated with adequately powered RCTs and by measuring the feasibility of implementation, acceptability, and effectiveness of exercise interventions on recognised QOL outcome measures. Future research should consider and address the methodological limitations of the published research 
This is an Accepted Manuscript of an article published by Taylor \& Francis in Brain Injury on 15 Nov 2020, available online: https://doi.org/10.1080/02699052.2020.1812117

to improve research quality. Specifically, estimating random variability when reporting methodology, and ensuring that group allocations are randomised.

\section{Limitations}

Due to the limited literature available in this area, the broad inclusion criteria allowed for three ${ }^{(26-28)}$ studies which included not solely TBI populations. As such there were some neurological disorder groups that included TBI but it was not possible to separate these data. The heterogeneity of the control groups across the included studies was another limitation, which could affect the reported improvements when between-group analyses were conducted. In addition, four studies ${ }^{(27,28,35,37)}$ failed to present the injury severity, so we were unable to distinguish between the sub-categories of brain injuries in the results. Another limitation of this review was that not all included studies were RCTs, hence it was not possible to draw definitive conclusions on effectiveness. During this review it became apparent that defining QOL was a more challenging task than first anticipated, and the tools used to assess QOL were very broad throughout the studies. This firstly led to the broad inclusion of what constituted as QOL or QOL domain and the divergence of QOL tools administered across all 13 studies. This made it difficult to accurately compare effects of QOL because of exercise interventions and diverse recommendations to the optimum QOL tools. Ideally, the included studies would have all used the same QOL tools allowing a more accurate comparison of interventions. Future studies could explore QOL by breaking it down into distinct sub-categories.

Selection bias should also be considered which can occur when the probability of programme adoption or evaluation is correlated to the impact ${ }^{(51)}$. For the non-RCTs in this review, the allocation of participants to the exercise treatments can depend on an arbitrary decision made by the investigator rather than by chance. Because of this, treatment outcomes cannot be 
This is an Accepted Manuscript of an article published by Taylor \& Francis in Brain Injury on 15 Nov 2020, available online: https://doi.org/10.1080/02699052.2020.1812117

compared for relevant prognostic factors at baseline without generating bias. In addition, as all the participants were volunteers, self-selection bias may be present. This is when the individuals that volunteer for a study differ from those who do not volunteer in terms of relevant clinical characteristics ${ }^{(51)}$. So, for example individuals who volunteer may possess higher levels of motivation to recover, or to undertake moderately vigorous exercise, which in turn could lead to greater attendance rates and better QOL outcomes. However, this may not be generalisable to the whole TBI population. Therefore, this should be considered when analysing data and interpreting the outcomes of this review. Selection bias does not occur in RCTs as participants are randomised into treatment arms, emphasising the need for more robust RCTs to establish reliable comparisons between studies.

\section{Conclusion}

The findings from this review highlight that there appear to be some modest improvements in QOL domains, including self-esteem, pain, personal relationships and better psycho-social reintegration, following structured exercise interventions. The certainty of these findings is limited due to the small number of relevant studies, plus the marked heterogeneity of study groups recruited and the diversity of exercise-based interventions. Nonetheless, some commonality findings emerged, such as the benefits of short-term, supervised combined aerobic and strengthening exercise interventions, performed at a moderate/ vigorous intensity, least three times weekly for up to 60 minutes. These findings are preliminary and further studies, specifically longer term, community based RCTs, are required to improve study quality and to build the evidence base for the effectiveness of exercise on QOL. 
This is an Accepted Manuscript of an article published by Taylor \& Francis in Brain Injury on 15 Nov 2020, available online: https://doi.org/10.1080/02699052.2020.1812117

\section{References}

1. Langlois JA, Rutland-Brown W, Wald MM. The epidemiology and impact of traumatic brain injury: a brief overview. The Journal of Head Trauma Rehabilitation 2006; 21(5): 375-378.

2. Corrigan JD, Selassie AW, Orman JAL. The epidemiology of traumatic brain injury. The Journal of Head Trauma Rehabilitation 2010; 25(2): 72-80.

3. Shavelle RM, Strauss D, Whyte J, Day SM, Yu YL. Long-term causes of death after traumatic brain injury. American Journal of Physical Medicine \& Rehabilitation 2001; 80(7): 510-516.

4. Horner MD, Ferguson PL, Selassie AW, Labbate LA, Kniele K, Corrigan JD. Patterns of alcohol use 1 year after traumatic brain injury: a population-based, epidemiological study. Journal of the International Neuropsychological Society 2005; 11(3): 322-330.

5. Holsinger T, Steffens DC, Phillips C, et al. Head injury in early adulthood and the lifetime risk of depression. Archives of General Psychiatry 2002; 59(1): 17-22.

6. Plassman BL, Havlik RJ, Steffens DC, et al. Documented head injury in early adulthood and risk of Alzheimer's disease and other dementias. Neurology 2000; 55(8): 1158-1166.

7. Hammond FM, Davis CS, Cook JR, Philbrick P, Hirsch MA. Relational dimension of irritability following traumatic brain injury: a qualitative analysis. Brain injury 2012; 1;26(11):1287-96.

8. Gilworth G, Carey A, Eyres S, Sloan J, Rainford B, Bodenham D, Neumann V, Tennann A. Screening for job loss: development of a work instability scale for traumatic brain injury. Brain Injury 2006; 20(8), 835-843. 
This is an Accepted Manuscript of an article published by Taylor \& Francis in Brain Injury on 15 Nov 2020, available online: https://doi.org/10.1080/02699052.2020.1812117

9. Oddy M, Moir JF, Fortescue D, Chadwick S. The prevalence of traumatic brain injury in the homeless community in a UK city. Brain injury 2012; 26(9), 1058-1064.

10. Whoqol Group. The World Health Organization quality of life assessment (WHOQOL): position paper from the World Health Organization. Social Science \& Medicine 1995; 41(10): 1403-1409.

11. Koskinen S. Quality of life 10 years after a very severe traumatic brain injury (TBI): the perspective of the injured and the closest relative. Brain injury 1998; 12(8), 631-648.

12. Kolakowsky-Hayner SA, Miner KD, Kreutzer JS. Long-term life quality and family needs after traumatic brain injury. The Journal of head trauma rehabilitation 2001; 16(4), 374-385.

13. Andelic N, Hammergren N, Bautz-Holter E, Sveen U, Brunborg C, Røe C. Functional outcome and health-related quality of life 10 years after moderate-to-severe traumatic brain injury. Acta Neurologica Scandinavica 2009; 120(1): 16-23.

14. Dijkers MP. Quality of life after traumatic brain injury: a review of research approaches and findings. Archives of Physical Medicine and Rehabilitation 2004; 85: 21-35.

15. Fletcher GF, Landolfo C, Niebauer J, Ozemek C, Arena R, Lavie CJ. Promoting Physical Activity and Exercise: JACC Health Promotion Series. Journal of the American College of Cardiology 2018; 72(14), 1622-1639.

16. Owen N, Healy GN, Matthews CE, Dunstan DW. Too much sitting: the population-health science of sedentary behaviour. Exercise and sport sciences reviews $2010 ; 38(3), 105$. 
This is an Accepted Manuscript of an article published by Taylor \& Francis in Brain Injury on 15 Nov 2020, available online: https://doi.org/10.1080/02699052.2020.1812117

17. Conn VS. Depressive symptom outcomes of physical activity interventions: meta-analysis findings. Annals of behavioral Medicine 2010; 39(2), 128-138.

18. Guiney H, Machado L. Benefits of regular aerobic exercise for executive functioning in healthy populations. Psychonomic bulletin \& review 2013; 20(1): 73-86.

19. Cotman CW, Berchtold NC. Exercise: a behavioral intervention to enhance brain health and plasticity. Trends in Neurosciences 2002; 25(6): 295-301.

20. O'neill J, Hibbard MR, Broivn M, et al. The effect of employment on quality of life and community integration after traumatic brain injury. The Journal of Head Trauma Rehabilitation 1998; 13(4): 68-79.

21. Webb CR, Wrigley M, Yoels W, Fine PR. Explaining quality of life for persons with traumatic brain injuries 2 years after injury. Archives of Physical Medicine and Rehabilitation 1995; 76(12): 1113-1119.

22. Ströhle A. Physical activity, exercise, depression and anxiety disorders. Journal of Neural Transmission 2009; 116(6): 777.

23. Moher D, Liberati A, Tetzlaff J, Altman DG. Preferred reporting items for systematic reviews and meta-analyses: the PRISMA statement. Annals of internal medicine $2009 ; 151(4), 264-269$.

24. Cherry MG, Perkins E, Dickson R, Boland A. Reviewing qualitative evidence. Doing a Systematic Review: A Student's Guide. Sage Publications, London 2014; 141-158.

25. Downs SH, Black N. The feasibility of creating a checklist for the assessment of the methodological quality both of randomised and non-randomised studies of health care interventions. Journal of Epidemiology \& Community Health 1998; 52(6): 377-384. 
26. Bateman A, Culpan FJ, Pickering AD, Powell JH, Scott OM, Greenwood RJ. The effect of aerobic training on rehabilitation outcomes after recent severe brain injury: a randomized controlled evaluation. Archives of Physical Medicine and Rehabilitation $2001 ; 82(2): 174-182$.

27. Driver S, Rees K, O'Connor J, Lox C. Aquatics, health-promoting self-care behaviours and adults with brain injuries. Brain Injury 2006; 20(2): 133-141.

28. Elsworth C, Winward C, Sackley C, et al. Supported community exercise in people with long-term neurological conditions: a phase II randomized controlled trial. Clinical Rehabilitation 2011; 25(7): 588-598.

29. Hassett LM, Moseley AM, Tate RL, Harmer AR, Fairbairn TJ, Leung J. Efficacy of a fitness centre-based exercise programme compared with a home-based exercise programme in traumatic brain injury: a randomized controlled trial. Journal of rehabilitation medicine 2009; 41(4): 247-255.

30. Hoffman JM, Bell KR, Powell JM, et al. A randomized controlled trial of exercise to improve mood after traumatic brain injury. Archives of Physical Medicine and Rehabilitation 2010; 2(10): 911-919.

31. Bellon K, Kolakowsky-Hayner S, Wright J, Huie H, Toda K, Bushnik T, Englander J. A home-based walking study to ameliorate perceived stress and depressive symptoms in people with a traumatic brain injury. Brain injury 2015; 29(3): 313-319.

32. Blake H, Batson,M. Exercise intervention in brain injury: a pilot randomized study of Tai Chi Qigong. Clinical Rehabilitation 2009; 23(7): 589-598. 
33. Kleffelgaard I, Soberg HL, Bruusgaard KA, Tamber AL, Langhammer B. Vestibular rehabilitation after traumatic brain injury: case series. Physical Therapy 2016; 96(6): 839-849.

34. Schwandt M, Harris JE, Thomas S, Keightley M, Snaiderman A, Colantonio A. Feasibility and effect of aerobic exercise for lowering depressive symptoms among individuals with traumatic brain injury: a pilot study. The Journal of Head Trauma Rehabilitation 2012; 27(2): 99-103.

35. Damiano DL, Zampieri C, Ge J, Acevedo A, Dsurney J. Effects of a rapid-resisted elliptical training program on motor, cognitive and neurobehavioral functioning in adults with chronic traumatic brain injury. Experimental Brain Research 2016; 234(8): 2245-2252.

36. Chin LM, Keyser RE, Dsurney J, Chan L. Improved cognitive performance following aerobic exercise training in people with traumatic brain injury. Archives of Physical Medicine and Rehabilitation 2015; 96(4): 754-759.

37. Lee YSC, Ashman T, Shang A, Suzuki W. Brief report: Effects of exercise and self-affirmation intervention after traumatic brain injury. NeuroRehabilitation 2014; 35(1): 57-65.

38. Weinstein AA, Chin LM, Collins J, Goel D, Keyser RE, Chan L. Effect of aerobic exercise training on mood in people with traumatic brain injury: a pilot study. The Journal of head trauma rehabilitation 2017; 32(3): E49.

39. Riebe D, Ehrman JK, Liguori G, Magal M, American College of Sports Medicine (Eds.). ACSM's guidelines for exercise testing and prescription 2018; Wolters Kluwer. 
This is an Accepted Manuscript of an article published by Taylor \& Francis in Brain Injury on 15 Nov 2020, available online: https://doi.org/10.1080/02699052.2020.1812117

40. Durstine JL. ACSM's exercise management for persons with chronic diseases and disabilities. Human Kinetics 10\% 2009.

41. Wise EK, Hoffman JM, Powell JM, Bombardier CH, Bell KR. Benefits of exercise maintenance after traumatic brain injury. Archives of physical medicine and rehabilitation 2012; 93(8), 1319-1323.

42. Lew HL, Poole JH, Guillory SB, Salerno RM, Leskin G, Sigford B. Persistent problems after traumatic brain injury: The need for long-term follow-up and coordinated care. Journal of rehabilitation research and development 2005; 43(2), vii-x.

43. Becker E, Bar-Or O, Mendelson L, Najenson T. Pulmonary functions and responses to exercise of patients following cranio cerebral injury. Scandinavian journal of rehabilitation medicine 1977; 10(2), 47-50.

44. Mossberg KA, Ayala D, Baker T, Heard J, Masel B. Aerobic capacity after traumatic brain injury: comparison with a nondisabled cohort. Archives of physical medicine and rehabilitation 2007; 88(3), 315-320.

45. Sullivan KA, Hills AP, Iverson GL. Graded Combined Aerobic Resistance Exercise (CARE) to Prevent or Treat the Persistent Post-concussion Syndrome. Current neurology and neuroscience reports 2018; 18(11), 75.

46. Van Praag H. Neurogenesis and exercise: past and future directions. Neuromolecular medicine 2008; 10(2), 128-140.

47. Leddy JJ, Kozlowski K, Donnelly JP, Pendergast DR, Epstein LH, Willer BA. Preliminary study of subsymptom threshold exercise training for refractory post-concussion syndrome. Clinical Journal of Sport Medicine 2010; 20(1), 21-27. 
This is an Accepted Manuscript of an article published by Taylor \& Francis in Brain Injury on 15 Nov 2020, available online: https://doi.org/10.1080/02699052.2020.1812117

48. Prangley A, Aggerholm M, Cinelli M. Improvements in balance control in individuals with PCS detected following vestibular training: A case study. Gait \& posture 2017; $58,229-231$.

49. Bergquist TF, Boll TJ, Corrigan JD, et al. Neuropsychological rehabilitation: Proceedings of a consensus conference. The Journal of Head Trauma Rehabilitation 1994; 9(4): 50-61.

50. Noll, H. H. (2004). Social indicators and Quality of Life research: Background, achievements and current trends. In Advances in sociological knowledge (pp. 151-181).

51. Tripepi G, Jager KJ, Dekker FW, Zoccali C. Selection bias and information bias in clinical research. Nephron Clinical Practice 2010; 115(2): c94-c99. 
This is an Accepted Manuscript of an article published by Taylor \& Francis in Brain Injury on 15 Nov 2020, available online: https://doi.org/10.1080/02699052.2020.1812117

Table 1. PICO model for formulating the clinical question.

\section{Criteria Determinants}

Population Only human adults with a TBI (exclusively a TBI population, or TBI participants within comparison groups).

Intervention Physical activity; or divided attention/ dual-tasking rehabilitation; or exercise training.

Comparison Treated with exercise intervention vs. untreated or participants received alternative rehabilitation (e.g., relaxation); people with TBI vs. healthy or individuals with other traumas; comparisons made between different severities of TBI (e.g., mild, moderate, severe); or comparison based on pre- or post-injury characteristics.

Outcomes QOL or health-related QOL (HRQOL) relating to at least one of the following domains: physical functioning, mental functions, socio-economic function, pain, vitality, overall life satisfaction and/or general health perceptions 
Table 2. Methodological quality assessment scoring using an assessment tool for randomised and non-randomised trials (Downs \& Black, 1998).

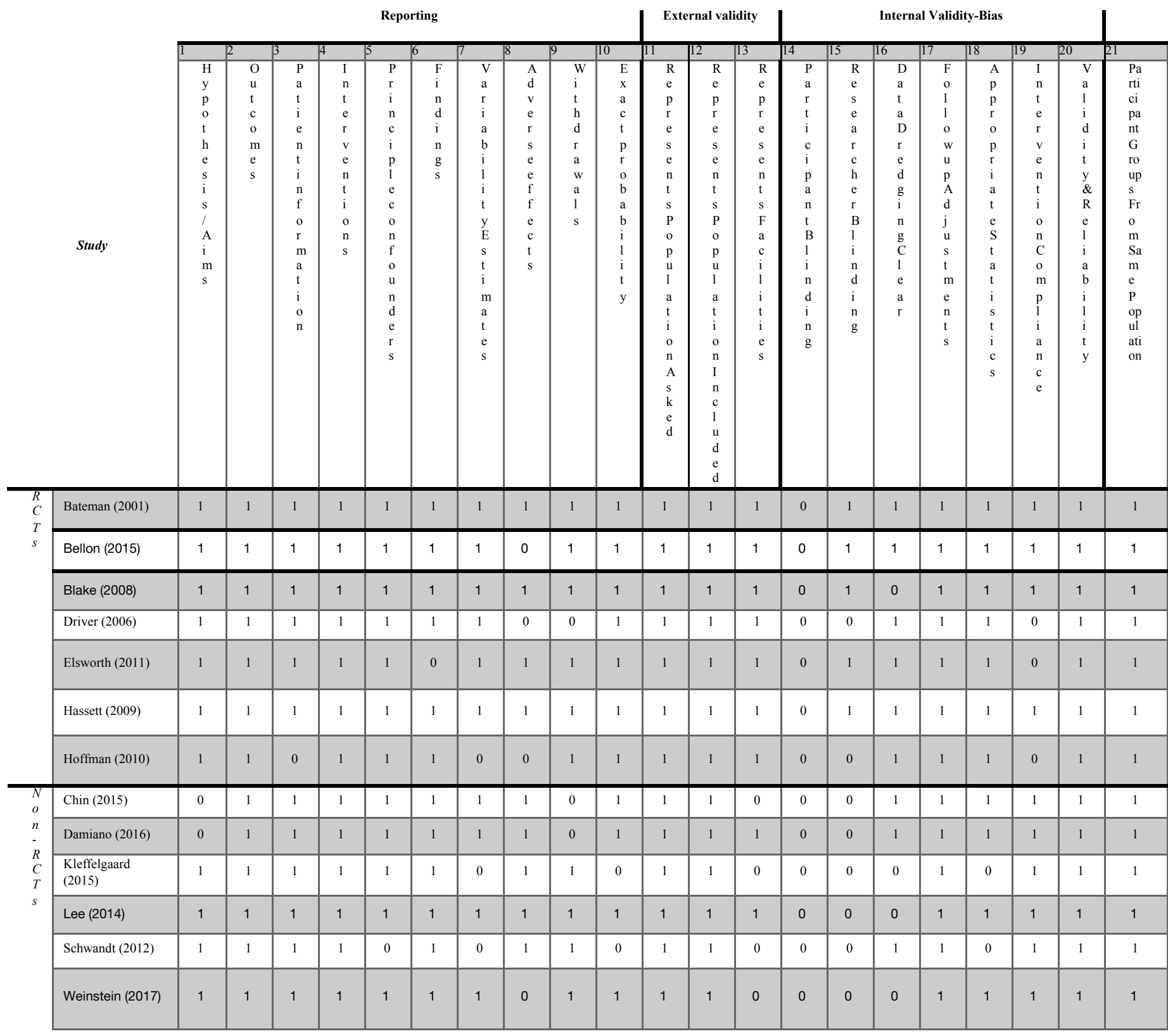

$1=$ Yes, item addressed appropriately, $0=$ No, item not addressed or unable to determine. Q5 $1 x=$ partially addressed, $2=i t e m$ addressed appropriately

Table 3. Study characteristics and population data for included studies

\begin{tabular}{|c|c|c|c|c|c|c|c|c|}
\hline & \multirow[t]{2}{*}{ Author } & \multirow[t]{2}{*}{$\begin{array}{l}\text { Country } \\
\text { of origin }\end{array}$} & \multirow{2}{*}{$\begin{array}{l}\text { Total } \\
\text { sample } \\
\text { size (n) }\end{array}$} & \multirow{2}{*}{$\begin{array}{l}\text { EX } \\
\text { group } \\
\text { sample } \\
\text { size (n) }\end{array}$} & \multirow[t]{2}{*}{ Gender } & \multicolumn{2}{|c|}{$\begin{array}{c}\text { Mean age } \\
\text { (years) }\end{array}$} & \multirow[t]{2}{*}{ Diagnosis and physical status } \\
\hline & & & & & & EX & CON & \\
\hline $\begin{array}{l}\mathbf{R} \\
\mathbf{C} \\
\mathbf{T} \\
\mathbf{S}\end{array}$ & $\begin{array}{l}\text { Bateman } \\
(2001)\end{array}$ & UK & 157 & 55 & $M \& F$ & 41.7 & 44.7 & $\begin{array}{l}\text { TBI ( } 22 \% \text { of total cohort), strok } \\
\text { haemorrhage, other. Long-term } \\
\text { inpatients with complex disabil } \\
\text { Able to sit on a cycle ergometer } \\
\text { physical, cognitive, or behaviou }\end{array}$ \\
\hline
\end{tabular}


Table 4. Intervention characteristics for included studies, detailing the exercise FITT principles (frequency, intensity, time, type), comparison groups, and the QOL outcome measures.

\begin{tabular}{|c|c|c|c|c|c|c|}
\hline & Study & $\begin{array}{l}\text { Intervention setting and exercise } \\
\text { type }\end{array}$ & $\begin{array}{l}\text { Duration } \\
\text { (week) }\end{array}$ & $\begin{array}{l}\text { Frequency } \\
\text { (per week) }\end{array}$ & $\begin{array}{l}\text { Time } \\
\text { (per } \\
\text { session- } \\
\text { min) } \\
\end{array}$ & Intensity \\
\hline \multirow{7}{*}{$\begin{array}{l}\mathbf{R} \\
\mathbf{C} \\
\mathbf{T} \\
\mathbf{S}\end{array}$} & $\begin{array}{l}\text { Bateman } \\
(2001)\end{array}$ & $\begin{array}{l}\text { Rehabilitation Centre Inpatients. } \\
\text { Aerobic exercise programme } \\
\text { (stationary cycling) }\end{array}$ & 12 & 3 & 30 & $60-80 \%$ HRmax \\
\hline & Bellon (2015) & $\begin{array}{l}\text { Home-based walking } \\
\text { programme. Pedometer } \\
\text { measuring steps }\end{array}$ & 12 & NR & NR & $\begin{array}{l}5 \% \text { weekly step } \\
\text { increase }\end{array}$ \\
\hline & Blake (2008) & $\begin{array}{l}\text { Supervised Tai Chi (Qigong - } \\
\text { integrating posture, movement, } \\
\text { breathing techniques) }\end{array}$ & 8 & 1 & 60 & NR \\
\hline & Driver (2006) & $\begin{array}{l}\text { Community-based exercise } \\
\text { programme. Unspecified } \\
\text { Aerobic and resistance } \\
\text { programme (aquatic -based) }\end{array}$ & 8 & 3 & 60 & $50-70 \%$ HRmax \\
\hline & $\begin{array}{l}\text { Elsworth } \\
\text { (2011) }\end{array}$ & $\begin{array}{l}\text { Cardiovascular, strength and } \\
\text { flexibility training } \\
\text { (Community-based gymnasium } \\
\text { exercise) }\end{array}$ & 12 & $\begin{array}{l}\text { At least one } \\
\text { session }\end{array}$ & NR & NR \\
\hline & Hassett (2009) & $\begin{array}{l}\text { Cardiorespiratory (primarily } \\
\text { walking/jogging) and strength } \\
\text { training (community-based } \\
\text { gymnasium exercise with } \\
\text { personal trainer supervision) }\end{array}$ & 12 & 3 & 60 & $\begin{array}{l}\text { Moderate to } \\
\text { vigorous } \\
\text { intensity (heavy } \\
\text { breathing but } \\
\text { able to talk) }\end{array}$ \\
\hline & $\begin{array}{l}\text { Hoffman } \\
(2010)\end{array}$ & $\begin{array}{l}\text { Aerobic-based exercise } \\
\text { (running, steps, rowing, cycling) } \\
\text { Partly supervised, community, } \\
\text { gymnasium- based. }\end{array}$ & 10 & $\begin{array}{l}5 \text { sessions } \\
\quad(1 \mathrm{x} \\
\text { supervised } \\
\text { session })\end{array}$ & 30 & $60 \%$ HRmax \\
\hline $\begin{array}{l}\mathbf{N} \\
\mathbf{o} \\
\mathbf{n}\end{array}$ & Chin (2015) & $\begin{array}{l}\text { Supervised Aerobic exercise } \\
\text { (treadmill walking). Medical } \\
\text { research Centre. }\end{array}$ & 12 & 3 & 30 & $70-80 \%$ HRR \\
\hline $\begin{array}{l}- \\
\mathbf{R} \\
\mathbf{C} \\
\mathbf{T}\end{array}$ & $\begin{array}{l}\text { Damiano } \\
(2016)\end{array}$ & $\begin{array}{l}\text { Unsupervised, home-based } \\
\text { exercise programme. Motor } \\
\text { control (training (elliptical } \\
\text { trainer) }\end{array}$ & 8 & 5 & 30 & $40-80 \mathrm{rpm}$ \\
\hline $\mathbf{s}$ & $\begin{array}{l}\text { Kleffelgaard } \\
(2015)\end{array}$ & $\begin{array}{l}\text { Hospital outpatient } \\
\text { rehabilitation. Supervised, } \\
\text { group-based, modified } \\
\text { vestibular Rehabilitation with } \\
\text { some strength and conditioning } \\
\text { activities (circuits) and } \\
\text { home-based aerobic exercise }\end{array}$ & 8 & 2 & $\begin{array}{l}1 \times 90 \\
1 \times 60\end{array}$ & NR \\
\hline
\end{tabular}




\begin{tabular}{llcccc}
\multicolumn{2}{l}{$\begin{array}{l}\text { programme (walking, jogging, } \\
\text { aquatics) }\end{array}$} & & & \\
& $\begin{array}{l}\text { Group supervised. IntenSati } \\
\text { workout (fusing high-energy } \\
\text { aerobics, martial arts, dance, } \\
\text { yoga, and strength conditioning) }\end{array}$ & 8 & 60 & NR \\
& $\begin{array}{l}\text { Outpatient medical rehabilitation } \\
\text { unit. Aerobic (cycling, } \\
\text { recumbent step, treadmill) }\end{array}$ & 12 & 3 & 30 & $60-75 \%$ HRmax \\
$(2012)$ & $\begin{array}{l}\text { Supervised aerobic exercise on } \\
\text { treadmill }\end{array}$ & 12 & 3 & 30 & $70-80 \%$ HRR \\
\hline $\begin{array}{l}\text { Weinstein } \\
(2017)\end{array}$ & & & & & \\
\hline
\end{tabular}

$B A I=$ Beck Anxiety Inventory, BBS = Berg Balance Scale, BDI-II = Beck Depression Index version 2, BICRO-39=Brain Injury Community Rehabilitation Outcome, BPI = Brief Pain Inventory, CES D = Centre of Epidemiological Studies-Depression, DASS $=$ Depression Anxiety Stress Scale, FIM = Functional Independence Measure, FSS = Fatigue Severity Scale, GHQ-12 = General Health Questionnaire, HADS = Hospital and Anxiety Scale, HAMD = Hamilton Depression inventory, HPLP II = Health Promoting Lifestyle Profile, HRmax = Maximum Heart Rate, HRR = Heart Rate Reserve, $n / a=$ Not applicable, NEADLI $=$ Nottingham Extended Activities of Daily Living scale, $N R=$ Not Reported, $P N A S=$ Positive and Negative Affect Scale, POMS = Profile of Mood States, PQOL $=$ Perceived Quality Of Life scale, PSDQ = Physical Self-Description Questionnaire, PSS = Perceived Stress Scale, PSQI = Pittsburg Sleep Quality Index, PTSD (PCL-C) = Post-Traumatic Stress Disorder (checklist-civilian version), QOLIBRI = Quality Of Life after Brain Injury, RMI = Rivermead mobility index, $R P Q=$ Rivermead Post-concussion symptoms Questionnaire, RSES = Rosenburg Self-Esteem Scale, SF-36 = Short Form questionnaire 36, TBI = Traumatic Brain Injury.

Table 5. The effects of the exercise interventions on overall QOL specific to TBI (in bold) and QOL domain outcome measures for each study.

\begin{tabular}{|c|c|c|c|c|c|c|c|}
\hline \multicolumn{2}{|r|}{ Study } & \multirow[t]{2}{*}{ Outcome measure } & \multicolumn{2}{|c|}{ Intervention } & \multirow{3}{*}{ Change } & \multicolumn{2}{|c|}{ Control } \\
\hline & & & Pre & Post & & Pre & Post \\
\hline $\mathbf{R}$ & Bateman (2001) & BSS & 39.6 & 46.5 & & 37.7 & 44.7 \\
\hline C & & RMI & 8.2 & 10.9 & 1 & 8.2 & 10.6 \\
\hline $\mathbf{T}$ & & Barthel index & 14.2 & 17.0 & 4 & 13.8 & 17.3 \\
\hline \multirow[t]{24}{*}{$\mathbf{s}$} & & FIM (total) & 88.9 & 105.6 & 4 & 85.7 & 101.4 \\
\hline & & NEADL & 43.4 & 32.1 & 4 & 44.1 & 32.5 \\
\hline & & HADS (anxiety) & 5.6 & 5.0 & 4 & 6.1 & 5.5 \\
\hline & & HADS (depression) & 5.7 & 5.5 & 4 & 6.6 & 5.8 \\
\hline & Bellon (2005) & CES-D & 16.1 & 12.0 & 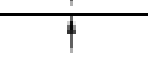 & 16.0 & 15.2 \\
\hline & & PSS & 25.6 & 20.8 & 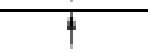 & 23.1 & 24.3 \\
\hline & Blake (2008) & GHQ-12 & 1.5 & $0.0^{*}$ & 1 & 3.5 & 2.5 \\
\hline & & PSDQ (self-esteem) & 2.8 & $3.4^{*}$ & 9 & 2.6 & 2.9 \\
\hline & Driver (2006) & HPLP-II & & & & & \\
\hline & & $-H R$ & 3.4 & $2.9^{*}$ & t & 2.4 & 2.4 \\
\hline & & -PA & 2.3 & $2.9^{*}$ & 4 & 2.4 & 2.3 \\
\hline & & -Nutrition & 2.4 & $0.6^{*}$ & 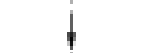 & 2.5 & 2.5 \\
\hline & & -SG & 2.5 & $2.9^{*}$ & 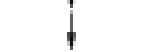 & 2.6 & 2.6 \\
\hline & & -IPR & 2.6 & $3.0^{*}$ & 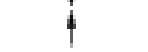 & 2.6 & 2.6 \\
\hline & & $-\mathrm{SM}$ & 2.8 & 2.8 & $=$ & 2.7 & 2.7 \\
\hline & & PSDQ (self-esteem) & 3.7 & $4.4 *$ & 4 & 3.8 & 3.8 \\
\hline & Elsworth (2011) & SF-36 & & & & & \\
\hline & & -Mental & 51.4 & 5.3 & 4 & 50.5 & 51.6 \\
\hline & & -Physical & 28.9 & 33.0 & 4 & 28.6 & 29.3 \\
\hline & & FSS & 4.4 & 4.1 & 4 & 4.4 & 4.2 \\
\hline & Hassett (2009) & DASS & & & & & \\
\hline & & -Depression & 1.0 & 5.0 & $\downarrow$ & 1.0 & 1.0 \\
\hline & & -Anxiety & 2.0 & 2.0 & $=$ & 2.0 & 1.0 \\
\hline & & -Stress & 3.0 & 4.0 & $\phi$ & 3.0 & 2.0 \\
\hline
\end{tabular}




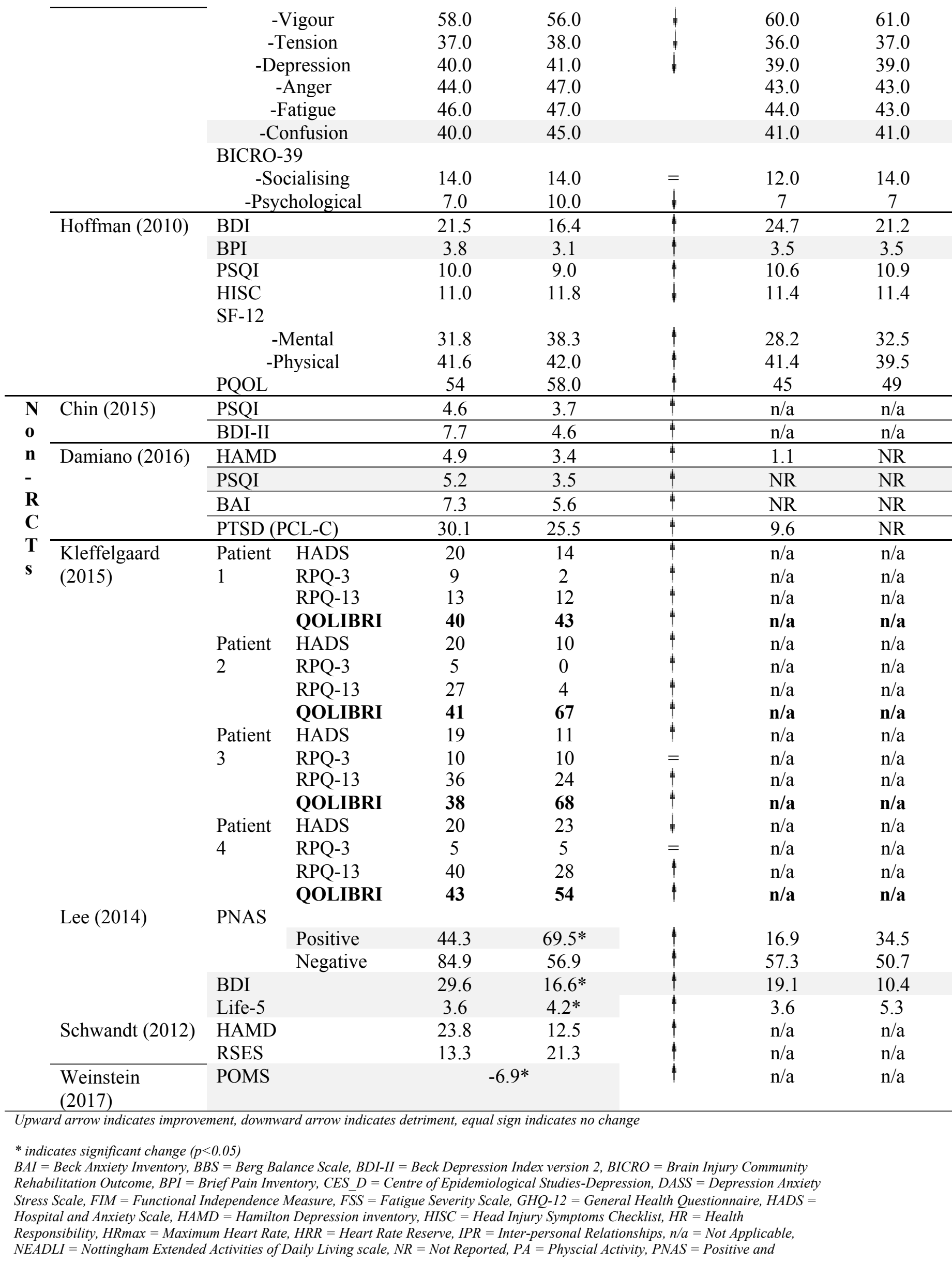


Negative Affect Scale, $P O M S=$ Profile of Mood States, $P Q O L=$ Perceived Quality Of Life scale, $P S D Q=$ Physical Self-Description Questionnaire, PSQI = Pittsburg Sleep Quality Index, PSS = Perceived Stress Scale, PTSD $(P C L-C)=$ Post-Traumatic Stress Disorder (checklist-civilian version), $Q O L I B R I=$ Quality Of Life after Brain Injury, $R M I=$ Rivermead mobility index, $R P Q=$ Rivermead

Post-concussion symptoms Questionnaire, RSES = Rosenburg Self-Esteem Scale, SF-36 = Short Form questionnaire 36, SG = Spiritual Growth, $S M=$ Stress Management, $T B I=$ Traumatic Brain Injury, 


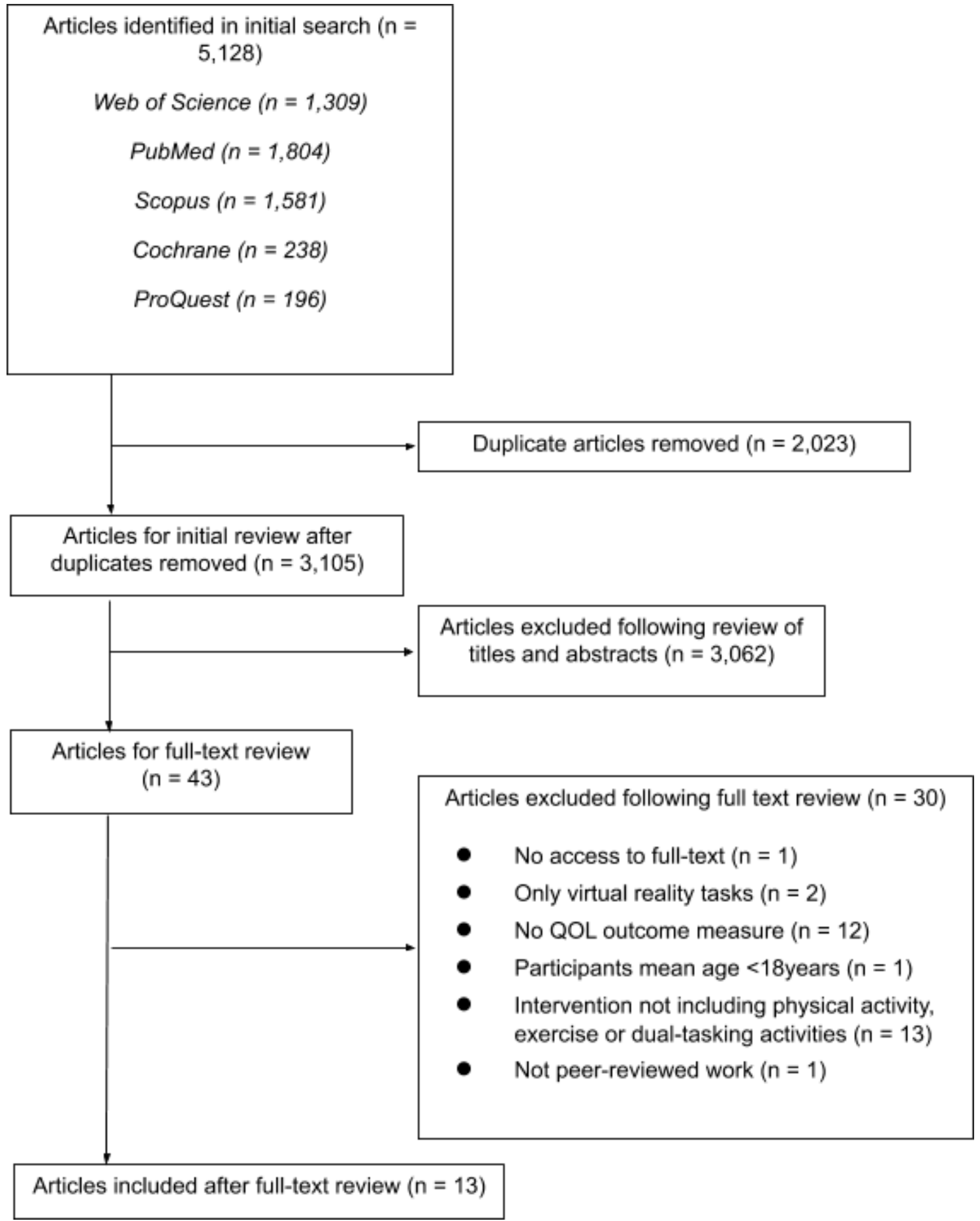

Figure 1. PRISMA flowchart of literature screening process. 


\section{Appendices}

Appendix 1. Search terms used for all five databases highlighting the Boolean operators 'OR', 'AND' and 'NOT'.

\section{Database Search Terms}

PubMed ("traumatic brain injury" OR "brain trauma" OR tbi OR "brain injury" OR "concussion" OR "head injury" OR "traumatic encephalopathy")) AND ("physical therapy" OR "exercise training" OR "physical activit*" OR "dual-task*" OR "divided attention" OR "rehabilitation")) AND ("quality of life" OR "psychometric" OR "depression" OR "health-related quality of life" OR “QoL" OR "life quality")) NOT "stroke"))

Web of TOPIC: ("traumatic brain injury" OR "brain trauma" OR "tbi" OR "brain injury" OR Science "concussion" OR "head injury" OR "traumatic encephalopathy") ANDTOPIC: ("physical therapy" OR "exercise training" OR "physical activit*" OR "dual-task*" OR "divided attention" OR "rehabilitation") ANDTOPIC: ("quality of life" OR "psychometric" OR "depression" OR "health-related quality of life" OR "QoL" OR "life quality") NOT TOPIC: ("stroke")

Scopus (TITLE-ABS-KEY("traumatic brain injury" OR "brain trauma" OR tbi OR "brain injury" Or "concussion" Or "head injury" OR "traumatic encephalopathy")) AND

(TITLE-ABS-KEY("physical therapy" OR "exercise training" OR "physical activit*" OR "dual task*" OR "divided attention" OR "rehabilitation")) AND (TITLE-ABS-KEY("quality of life" OR "psychometric" OR "depression" OR "health related quality of life" OR "QoL" OR "life quality")) AND NOT (TITLE-ABS-KEY("stroke"))

Cochrane "traumatic brain injury" OR "brain trauma" OR tbi OR "brain injury" OR "concussion" OR "head injury" OR "traumatic encephalopathy" and "physical therapy" OR "exercise training" OR "physical activit*" OR "dual task*" OR "divided attention" OR "rehabilitation" and "quality of life" OR "psychometric" OR "depression" OR "health related quality of life" Or "QoL" OR "life quality" not "stroke"

ProQuest all("traumatic brain injury" OR "brain trauma" OR "tbi" OR "brain injury" OR "concussion" OR "head injury" OR "traumatic encephalopathy") AND all("physical therapy" OR "exercise training" OR "physical activit*" OR "dual task*" OR "divided attention" OR "rehabilitation") AND all("quality of life" OR "psychometric" OR "depression" OR "health related quality of life" OR "QoL" OR "life quality") NOT all("stroke") 